\title{
The first case of aggressive mimicry among lamprologines in a new species of Lepidiolamprologus (Perciformes: Cichlidae) from Lake Tanganyika
}

\author{
ROBERT SCHELLY ${ }^{1}$, TETSUMI TAKAHASHI ${ }^{2}$, ROGER BILLS ${ }^{3} \&$ MICHIO HORI $^{2}$ \\ ${ }^{1}$ Department of Ichthyology, American Museum of Natural History, Central Park West at $79^{\text {th }}$ St., New York, NY 10024, USA. \\ E-mail: schelly@amnh.org \\ ${ }_{2}^{2}$ Department of Zoology, Graduate School of Science, Kyoto University, Kitashirakawa-Oiwakecho, Sakyo, Kyoto 606-8502, Japan. \\ E-mail:tetsumi@terra.zool.kyoto-u.ac.jp; hori@terra.zool.kyoto-u.ac.jp \\ ${ }^{3}$ South African Institute for Aquatic Biodiversity, Private Bag 1015, Grahamstown 6140, South Africa. E-mail: r.bills@ru.ac.za
}

\begin{abstract}
Lepidiolamprologus mimicus n. sp. is described from material collected along the Zambian coast of Lake Tanganyika. It is distinguished from congeners by its unique color pattern of bright yellow fins, a brownish-tan flank coloration and large, dark brown spots along the flanks, in addition to a series of meristic and morphometric characters. Lepidiolamprologus mimicus n. sp. exhibits an interesting feeding ecology, in which individuals blend into schools of their prey, yellow-finned cyprichromines, with the aid of similar coloration. This is the first instance of aggressive mimicry reported for lamprologines.
\end{abstract}

Key words: Lepidiolamprologus mimicus new species; Lamprologini; taxonomy; Lake Tanganyika; aggressive mimicry

\section{Introduction}

Lamprologine cichlids, recognized by Takahashi (2003) as one of 16 tribes constituting the Lake Tanganyika cichlid fauna, exhibit a broad range of morphological, ecological, and behavioral diversity (Stiassny 1997). New species of lamprologines from Tanganyika and associated rivers continue to be discovered (Hanssens \& Snoeks 2003; Schelly et al. 2003; Aibara et al. 2005). With about 80 described lacustrine species, lamprologines comprise roughly half of the cichlid species in Lake Tanganyika, where the group is most species rich. In addition to those of Lake Tanganyika, eight lamprologine species are known from the Congo River to the west, and one from the Malagarasi River to the east. Lamprologines are not known from outside of the greater Congo Drainage. Various lamprologine classifications (e.g. Pellegrin 1904; Regan 1920; Colombe \& Allgayer 1985; Poll 1986) have dealt with mostly superficial anatomy, and the group is in need of a classification based on a thorough phylogenetic analysis. Lamprologines are currently assigned to eight genera: Altolamprologus Poll 1986, Chalinochromis Poll 1974, Julidochromis Boulenger 1898, Lamprologus Schilthuis 1891, Lepidiolamprologus Pellegrin 1904, Neolamprologus Colombe and Allgayer 1985, Telmatochromis Boulenger 1898, and Variabilichromis Colombe and Allgayer 1985. This paper deals with a new species in the genus Lepidiolamprologus, considered by Poll (1986) to comprise the following superficially similar, elongate, predatory fishes characterized by high lateral line scale counts: L. elongatus (Boulenger 1898), L. cunningtoni (Boulenger 1906), L. attenuatus (Steindachner 1909), L. profundicola (Poll 1949), L. kendalli (Poll \& Stewart 1977), and L. nkambae (Staeck 1978). More recently, analyses based on molecular data (Sturmbauer et al. 1994; Schelly et al. 2006) and morphology (Stiassny 1997; Schelly, in press) have provided evidence that $L$. cunningtoni is not closely related to the remaining species assigned to Lepidiolamprologus. 


\section{Material and methods}

Collections and observations of the fish were made using SCUBA at depths of 10-30 $\mathrm{m}$. To capture the fish, they were first driven into monofilament ( $1 \mathrm{~cm}$ stretched mesh) standing nets ( $2 \mathrm{~m} \mathrm{X} 20 \mathrm{~m})$ and then retrieved by the diver with hand nets. Specimens were fixed in $10 \%$ formalin and preserved in either $50 \%$ isopropanol or $75 \%$ ethanol. Detailed ecological observations were made with SCUBA by MH on a daily basis during the month of November between 1995 and 2006. Meristic counts and morphometric measurements were made on the left side of specimens with digital calipers to $0.1 \mathrm{~mm}$, and followed Barel et al. (1977) with the following additions: dorsal and anal fin base length were measured along the dorsum or ventrum from the insertion of the first spine to the insertion of the last ray in the respective fin, pelvic fin length was measured from the insertion of the longest ray to its tip, pre-dorsal distance was measured from the premaxillary symphysis to the insertion of the first dorsal spine, pre-pectoral distance was measured from the premaxillary symphysis to the insertion of the middle pectoral ray, and pre-pelvic distance was measured from the mandibular symphysis to the insertion of the interior pelvic ray. Specimens were cleared and counterstained following Dingerkus and Uhler (1977). Some specimens, including the holotype, were radiographed to determine vertebral counts and fin elements. For comparison with the new species, portions of the type series of Lepidiolamprologus kendalli, L. nkambae and L. profundicola were examined.

Abbreviations

$\begin{array}{ll}\text { AMNH } & \text { American Museum of Natural History, New York, USA } \\ \text { FAKU } & \text { Kyoto University Museum, Kyoto, Japan } \\ \text { IRSNB } & \text { Institut Royal des Sciences Naturelles de Belgique, Bruxelles, Belgium } \\ \text { MCZ } & \text { Museum of Comparative Zoology, Cambridge, USA } \\ \text { MRAC } & \text { Musée Royal de l'Afrique Centrale, Tervuren, Belgium } \\ \text { SAIAB } & \text { South African Institute for Aquatic Biodiversity, Grahamstown, South Africa } \\ \text { Zm } & \text { Private collection of M. Hori, Kyoto University, Japan } \\ \text { BD } & \text { body depth } \\ \text { HL } & \text { head length } \\ \text { IW } & \text { interorbital width } \\ \text { NLF } & \text { neurocranial lateral line foramina } \\ \text { SL } & \text { standard length }\end{array}$

\section{Results}

Lepidiolamprologus mimicus new species

Figs. 1-5, Table 1

Holotype: SAIAB 41257, Chituta Bay, Zambia, at Chituta Bay cliffs, at 10-15 m depth along the rocky slope,

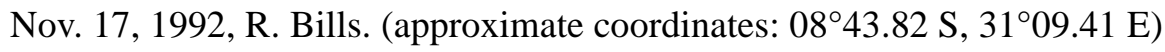

Paratypes: SAIAB 58308 ( $\mathrm{n}=1$; cleared and stained), collected with holotype; FAKU 95137 (male, 123.1 mm SL), FAKU 95138 (female, 121.7 mm SL), Kasenga, Zambia, 14 m depth, 7 Nov. 2005, gill net, M. Hori. FAKU 95139 (male, 159.7 mm SL), Kasenga, Zambia, 13-16 m depth, 3 Dec. 2005, gill net, M. Hori. FAKU 95140 (male, 119.4 mm SL), Kasenga, Zambia, 2-15 m depth, 30 Oct. 1996, gill net, M. Hori. FAKU 95141 (male, 129.6 mm SL), Kasenga, Zambia, 15 m depth, 12 Dec. 1996, gill net, H. Ochi. FAKU 95142 (male, 76.9 mm SL), Kasenga, Zambia, 19 m depth, 1 Nov. 1995, M. Hori. FAKU 95143 (male, 101.7 mm SL), off 
Mtondwe Is., Zambia, depth unknown, 1 Nov. 1995, gill net, M. Hori. FAKU 95144 (female, 133.6 mm SL), Kasenga, Zambia, 14-19 m depth, 13 Nov. 1995, gill net, M. Hori. FAKU 95145 (male, 147.0 mm SL), FAKU 95146 (female, 130.7 mm SL), Kasenge, Zambia, 15 m depth, 11 Jan. 1994, gill net, M. Hori.
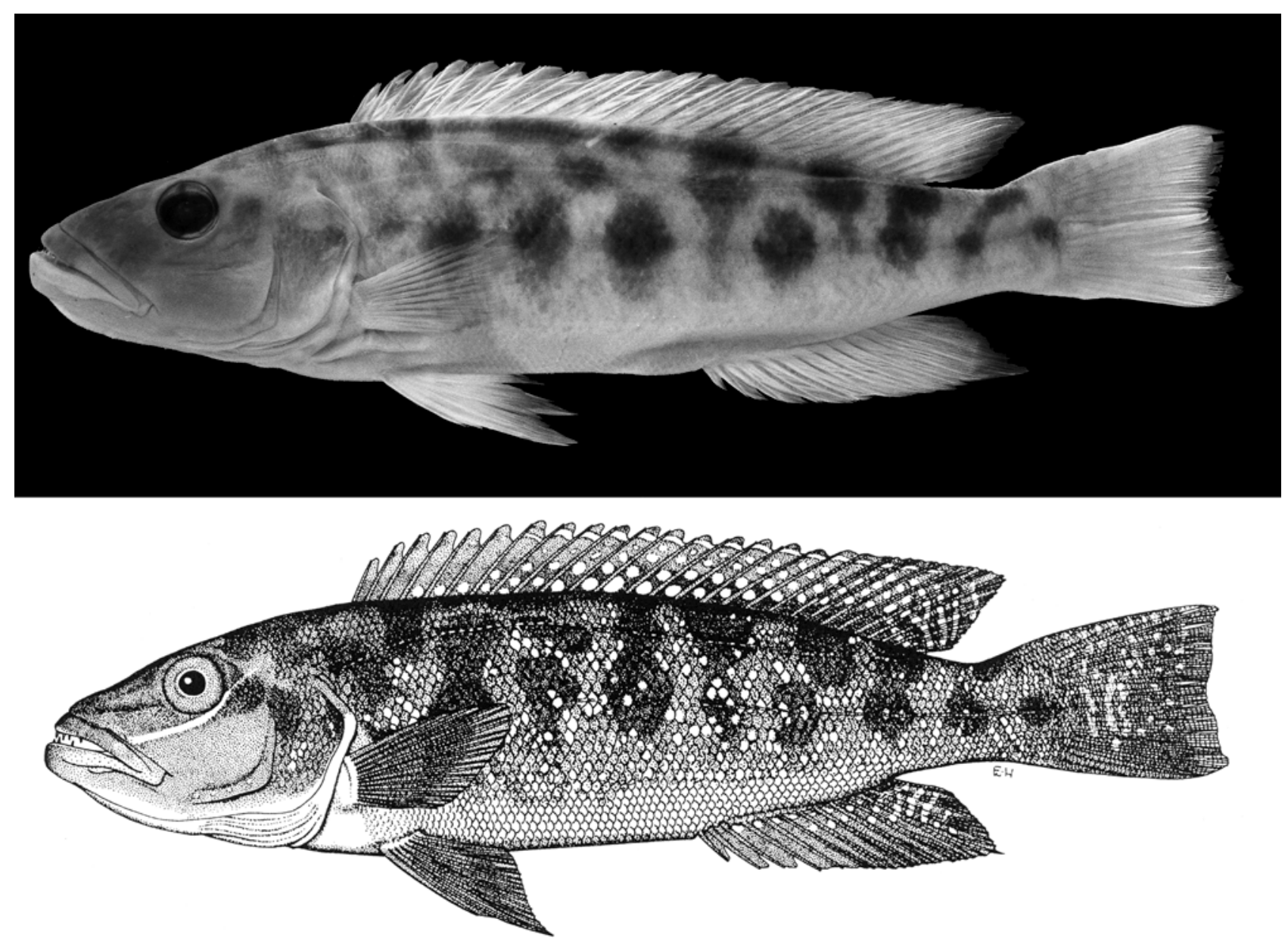

FIGURE 1. Lepidiolamprologus mimicus $\mathbf{n}$. sp., holotype, SAIAB 41257, $144.8 \mathrm{~mm}$ SL, drawing by Elaine Heemstra.

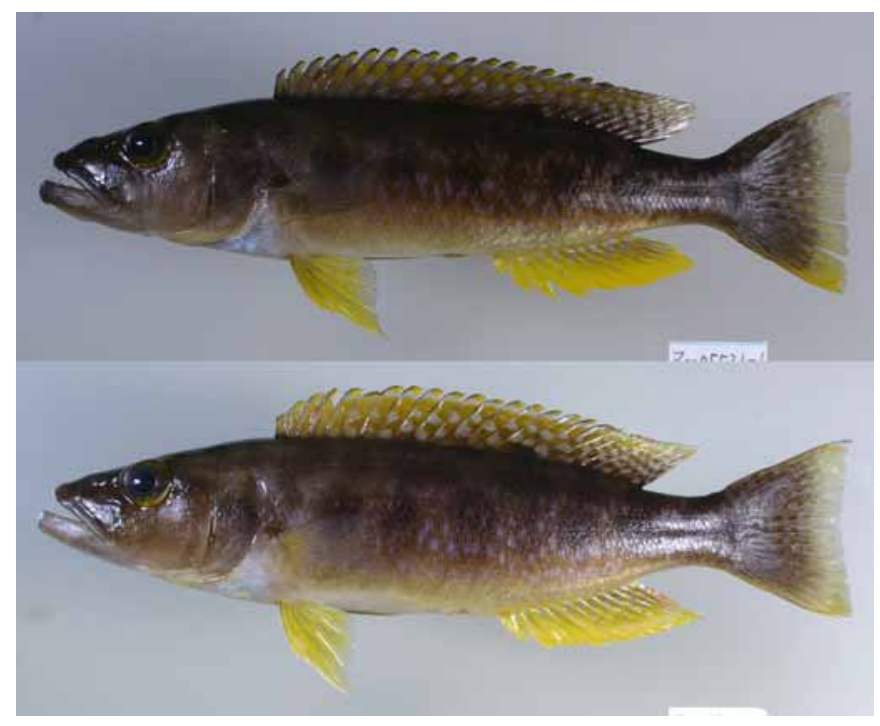

FIGURE 2. Photographs of Lepidiolamprologus mimicus $\mathbf{n}$. sp. collected from Kasenga, Zambia before fixation. (upper) Zm 05521-1, paratype, $123.1 \mathrm{~mm}$ SL, male. (lower) Zm 05521-2, paratype, $121.7 \mathrm{~mm}$ SL, female. Photo by TT. 

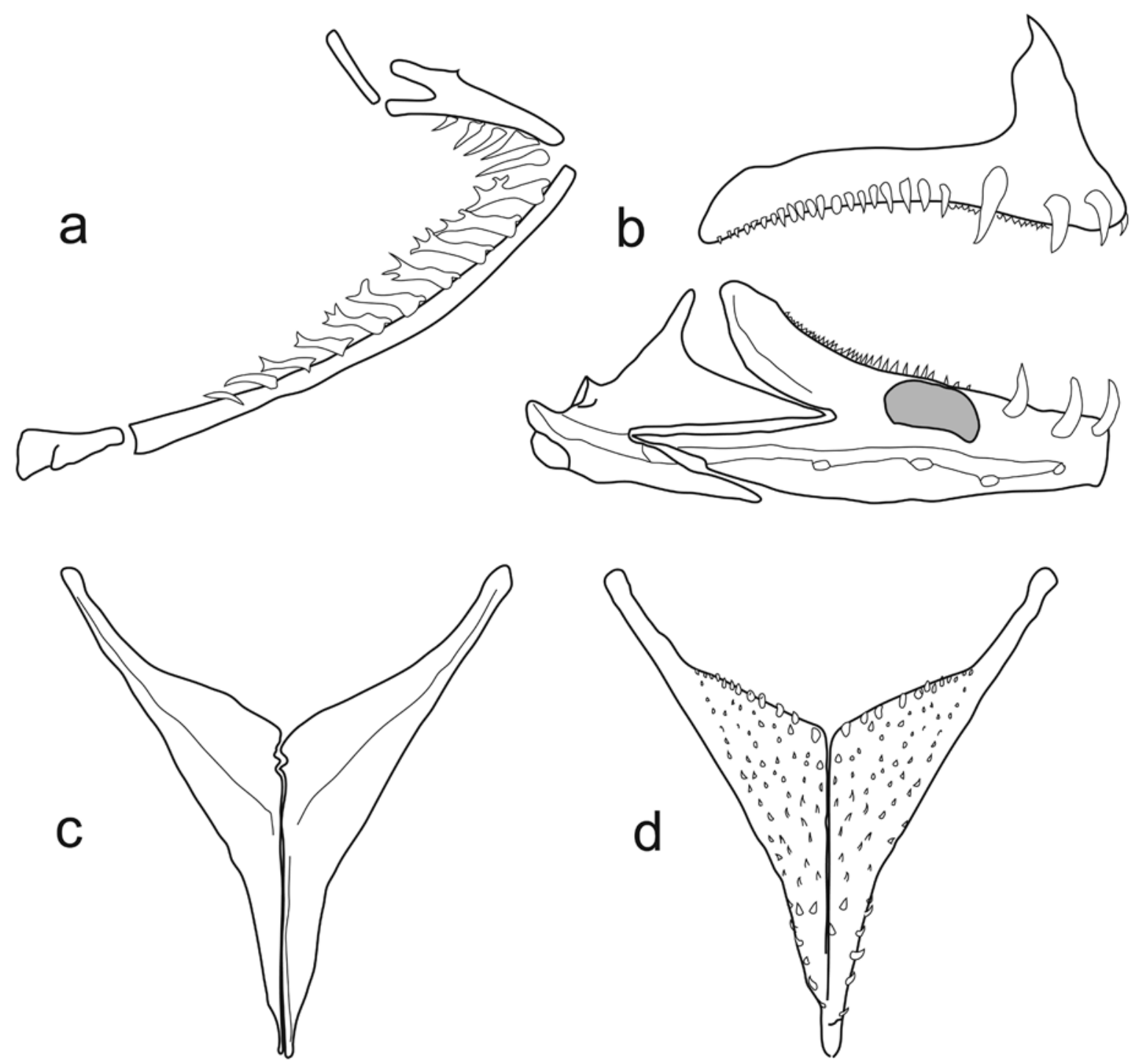

FIGURE 3. Lepidiolamprologus mimicus n. sp., paratype, SAIAB 58308, $96.1 \mathrm{~mm}$ SL: (a) first gill arch, (b) premaxilla and dentary with anguloarticular, labial ossification in gray, (c) lower pharyngeal jaw ventral view, (d) lower pharyngeal jaw dorsal view.

Differential diagnosis. From the Lepidiolamprologus sensu Poll (1986), Lepidiolamprologus mimicus n. sp. is distinguished from L. cunningtoni by, among numerous other neurocranial and gill arch characters, possession of a sesamoid bone in the labial ligament, 2 pores at NLF0, and a color pattern based on three rows of irregular spots, whereas $L$. cunningtoni lacks a labial ossification, has a single, coalesced NLF0 pore, and a color pattern based on a series of faint bars. With the other five members of Poll's Lepidiolamprologus, $L$. mimicus $\mathbf{n}$. sp. shares a whole suite of neurocranial, gill arch, and coloration characters, but is still easily distinguishable. Of these species, it is unique in having bright yellow fins and very dark, large spots on the flanks, without additional small spots or a complex pattern of spots and worm lines on the head (as in L. nkambae and L. kendalli). Lepidiolamprologus mimicus n. sp. is somewhat deeper-bodied than L. nkambae, $L$. kendalli, and L. attenuatus (BD 23.4-26.2\% SL, vs. max 23.3\% SL in L. nkambae), has a more elongate head than L. attenuatus (HL 31.0-33.7\% SL, vs. 28.2-30.5\% SL in L. attenuatus), has one more vertebra than both L. nkambae and L. kendalli (34 vs. 33), and has a wider interorbital region (IW 17.4-24.5\% HL) than L. nkambae (IW 14.3-16.9\% HL) and L. kendalli (IW 14.3-17.8\% HL). In addition, it usually has one more dorsal fin ray than both L. nkambae and L. kendalli (11 vs. 10). The longitudinal line scale count of L. mimicus $\mathbf{n}$. sp. 
is almost always higher (73-79) than in L. attenuatus and L. elongatus (both 66-73), L. kendalli (67-70) and L. profundicola (66-74). Finally, L. mimicus n. sp. generally has fewer gill rakers (10-12) on the first ceratobranchial than L. elongatus (11-14) and L. attenuatus (13-15).

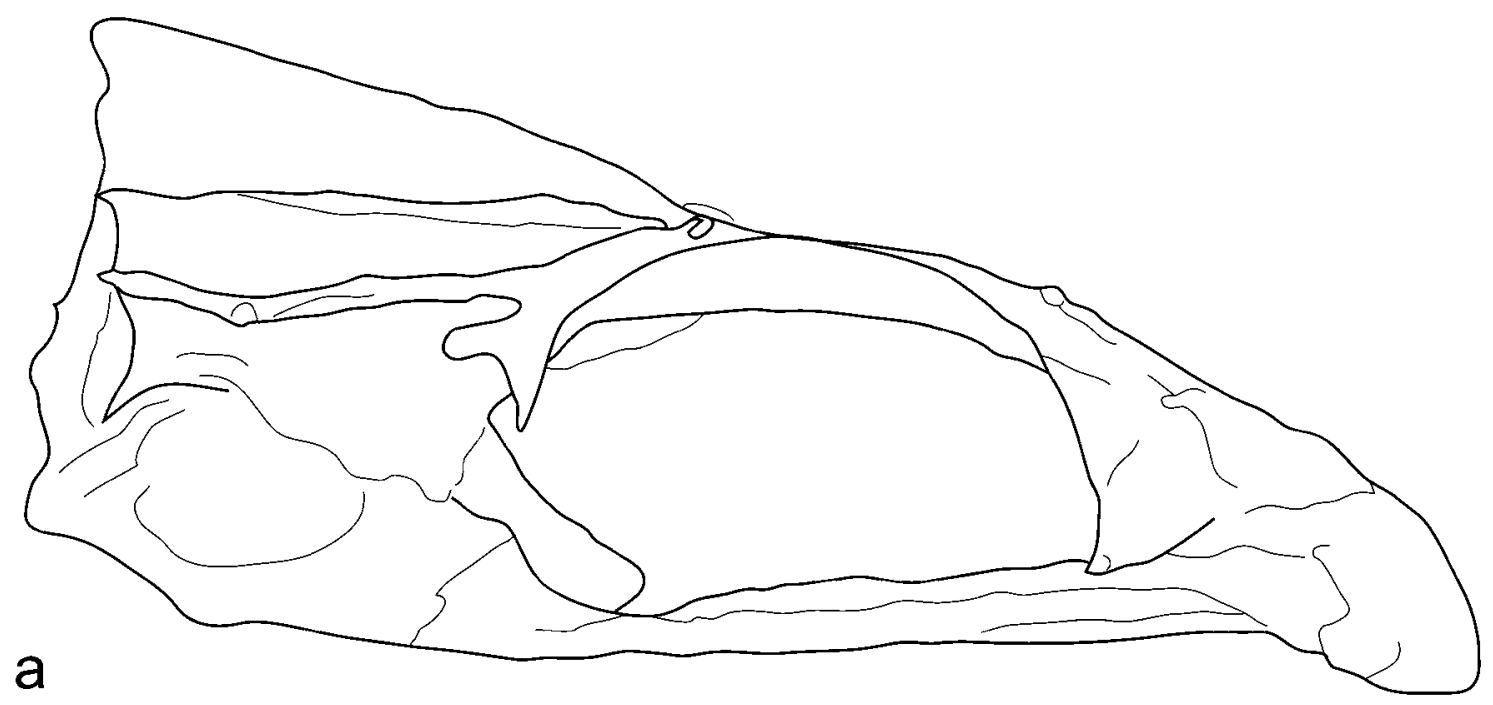

b

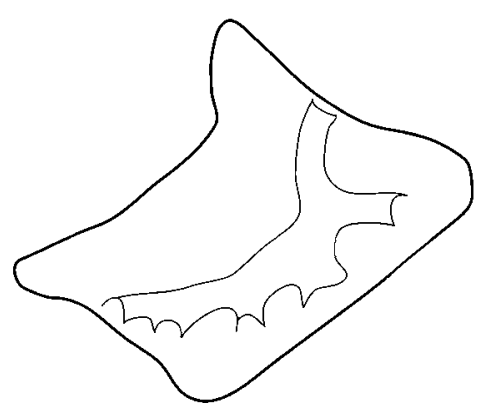

FIGURE 4. Lepidiolamprologus mimicus n. sp., paratype, SAIAB 58308, $96.1 \mathrm{~mm}$ SL: (a) neurocranium (b) lachrymal and dermosphenotic.

Description. Counts and measurements for the holotype and 12 paratypes given in Table 1. An elongate, moderately shallow-bodied species (BD 23.4-26.2, mean 24.7\% SL), with a large mouth and sleek form characteristic of an open-water piscivore. Greatest body depth at about base of fifth dorsal fin spine. Head length 31.0-33.7, mean 32.4\% SL. Head profile slightly convex, rising smoothly to dorsal fin base.

Fins. Dorsal fin XVIII 10-11, anal fin V 8-9. Spines in the dorsal fin increase gradually in length posteriorly until about the $7^{\text {th }}$ spine, after which they remain constant. Anal fin spines gradually increase posteriorly through entire series. Dorsal and anal fins come to a point and terminate at about the end of the caudal peduncle; no rays are produced. Caudal fin large and emarginate, with 14 branched rays. Pectoral and pelvic fins short, terminating well ahead of anus. First ray in pelvic fin is longest.

Jaws and Teeth (Fig. 2). Lower jaw prognathous, with both outer and inner row teeth pointed unicuspids in both jaws. Single series of enlarged, recurved, procumbent caniniform teeth (8 premaxillary and 6 dentary) situated on anterior third of both jaws, with largest teeth furthest from symphysis. Posterior to large teeth single rows of slightly enlarged caniniform teeth run almost whole length of dentigerous arms of both dentary and premaxilla, outer row on premaxilla with 49-60 teeth. Small, caniniform inner teeth in five to nine irregular rows nearest symphysis, tapering to single row posteriorly and running most of length of dentigerous arms of premaxilla and dentary. 
TABLE 1. Morphometric and Meristic data for Lepidiolamprologus mimicus n. sp.

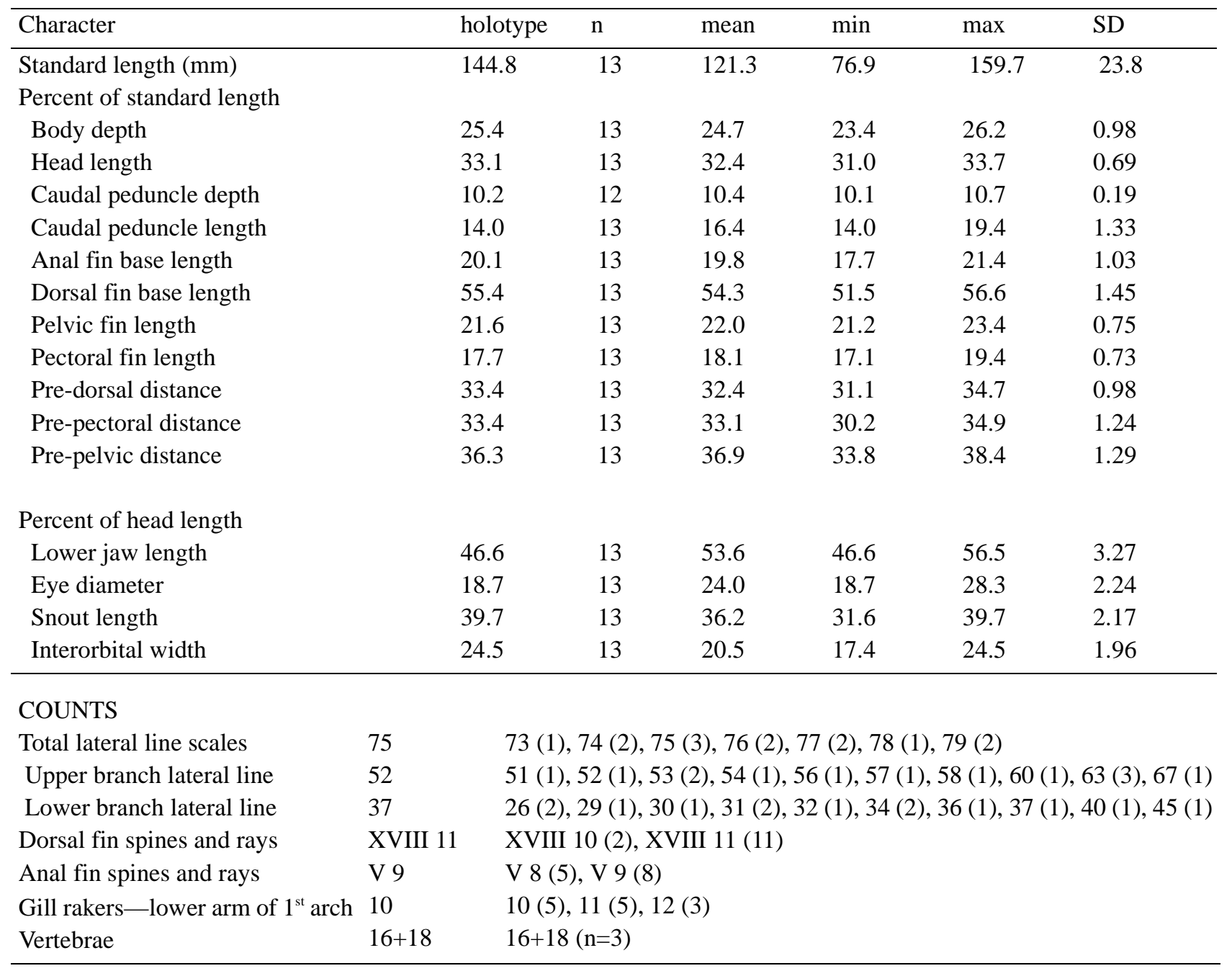

Gill rakers (Fig. 3a). Slender, elongate, and non-denticulate, with up to four subsidiary branches. Thirteen to 16 gill rakers along outer row of first gill arch. No rakers present on hypobranchial, 10-12 rakers along ceratobranchial, sometimes single raker in angle of arch, and 3-4 rakers on epibranchial.

Lower pharyngeal jaw (Fig. 3c, d). Longer than wide, with slight interdigitation along ventral suture. About 24 teeth in posterior tooth row. All teeth slender and beveled or hooked.

Scales. Flank scales small, ctenoid, and regularly imbricating. Lateral line scales 73-79, with 51-67 in upper and 26-45 in lower lateral line branch. Considerable overlap (16-20 scales) between upper and lower branches of lateral line. Cheek usually naked, but $4-5$ cheek scales observed in three of 13 individuals, small scales on belly and small, deeply embedded scales on chest. Opercle and subopercle heavily scaled. Caudal fin with scales extending more than half its length.

Vertebrae. $34 ; 16+18$.

Additional osteology (Figs. 3, 4). Infraorbital series comprised of broad, plate-like lachrymal with 6 large sensory canal pores, lacking infraorbitals adjacent to lachrymal. Dermosphenotic present. Labial ossification present. Single supraneural present. Supraoccipital crest well-developed and increasing in depth posteriorly, with sharply-angled posterior edge. No frontal ridge present, two distinct pores at NLF0. Frontal shelf welldeveloped and extending anteriorly beyond NLF2. Pre-orbital process of lateral ethmoid rotated posteromedially. Post-orbital process of sphenotic followed by a large, spoon-shaped wing. Frontal and ethmoidvomer continuous in profile, without abrupt drop-off. 

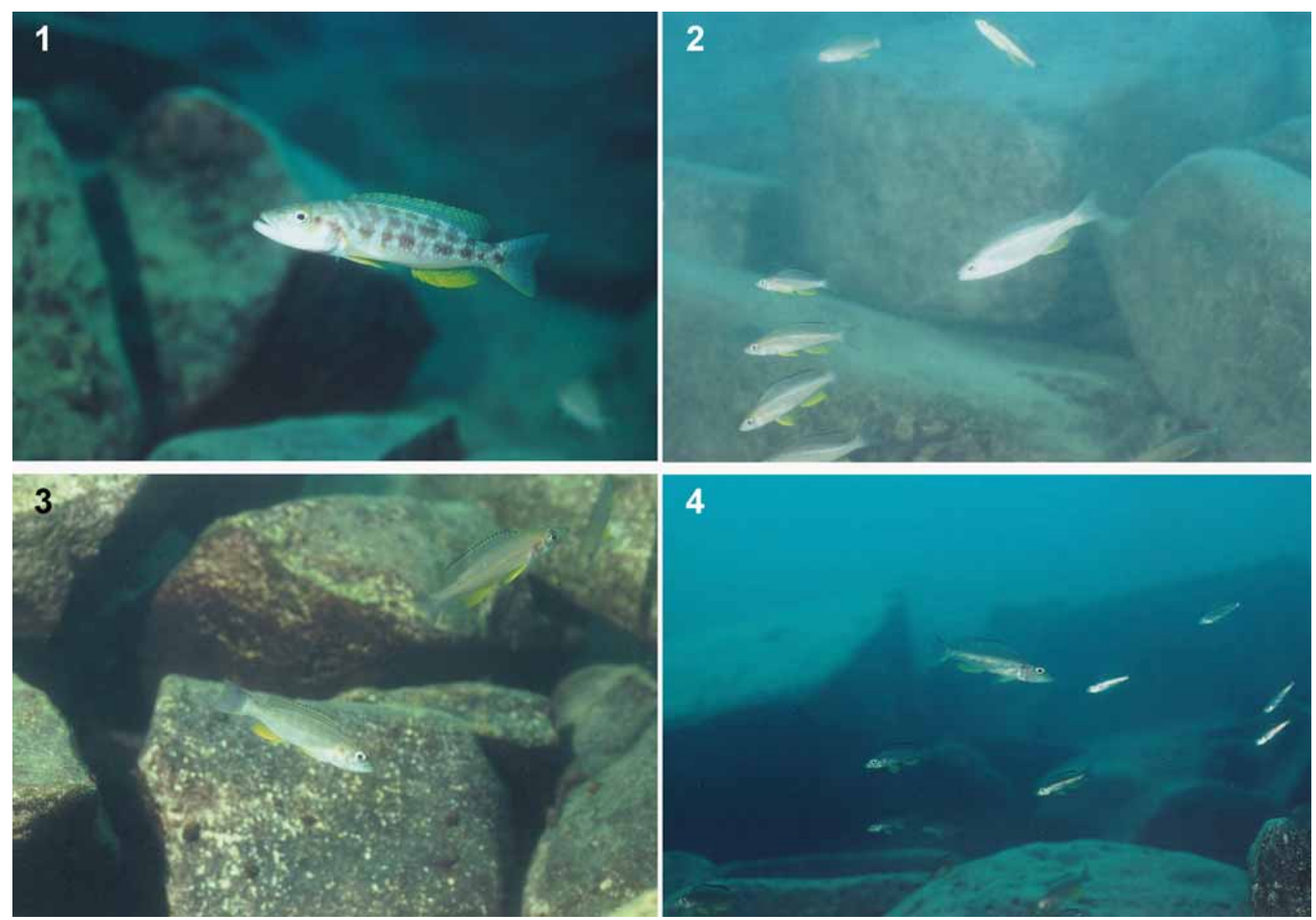

FIGURE 5. Photographs showing coloration of Lepidiolamprologus mimicus $\mathbf{n}$. sp. 1) The coloration of an adult at nonforaging time, 2) that of an adult at foraging time with females of Paracyprichromis brieni in background, 3) that of subadult with young of $P$. brieni in background, and 4 ) that of young with juveniles of $P$. brieni in background.

Coloration. In life, background body color brownish-tan, with three broken white to silvery-blue stripes composed of irregular blotchy spots. Superimposed over this pattern are three rows of seven to nine large, dark-brown spots stretching from above opercle to caudal flexure. Large spots irregular, with intervening space between them horizontally about as large as the spots. Vertically, some spots merge together partially, though some are staggered irregularly resulting in misalignment between horizontal rows. Largest spots in lower row, which is superimposed over the lower branch of lateral line at about center of flank, while middle row of slightly smaller spots is superimposed over upper lateral line branch. Top row of spots sits along dorsal fin base, with spots stretching partially onto dorsal fin. Opercle with a patch of lavender and a black blotch posteriorly, belly white, eyes with bright yellow dorsal and ventral bordering. Bluish-white, thin line running below eye from lachrymal to whitish patch on cheek. All fins with bright yellow; dorsal, anal, and caudal fins with rows of large yellow maculae interspersed with small patches of white. Yellow maculae blend together vertically to form series of yellow bands. Pectoral fin pale yellow on the base. Preserved coloration a uniform, light yellow-tan with brown spots in pattern described above. No sexual dimorphism in coloration.

Diet. Rocky littoral, open-water piscivore.

Ecology and behavior. (Fig. 5). Ecology and behavior of the holotype and paratypes was not recorded. However, these aspects of the biology of Lepidiolamprologus mimicus $\mathbf{n}$. sp. were studied at Kasenga from 1993 to 2006. Underwater observation during the period and analysis of stomach contents of samples revealed that this species was exclusively piscivorous and mainly preyed on young and sub-adults of cyprichromine cichlids. In the littoral region of Kasenga, four species of cyprichromine (Cyprichromis leptosoma, C. zona- 
tus, C. coloratus, and Paracyprichromis brieni) form mixed-species schools composed of various subgroups of age or sex of each species in open water 1-4 m above the rocky substrate (Takahashi et al. 2002, 2006). Usually L. mimicus n. sp. stalked solitarily near or mingled in the school at a depth of $10 \mathrm{~m}$ or more, and attacked mainly young and juveniles of the school. At least 30-40 individual hunts were observed. When hunting, adults of L. mimicus $\mathbf{n}$. sp. changed their body coloration markedly from dark-brown to pale beige; their characteristic dark-brown spots disappeared and rows of fine silver dots on the flank faded, but the yellow anal fin and black dotted line at the tip of the dorsal fin remained. This coloration generally looked like that of female cyprichromines and specifically very much resembled that of female Paracyprichromis brieni. The degree of resemblance in coloration of L. mimicus $\mathbf{n}$. sp. to its prey during hunting was greater in young and sub-adults than adults (Fig. 5-3, -4), and the predominant prey were young and juveniles of Paracyprichromis brieni, with small Cyprichromis making up the balance. These phenomena indicate both that $L$. mimicus n. sp. is highly specialized to forage on cyprichromine fishes and also that its coloration, especially during hunting, is a form of aggressive mimicry.

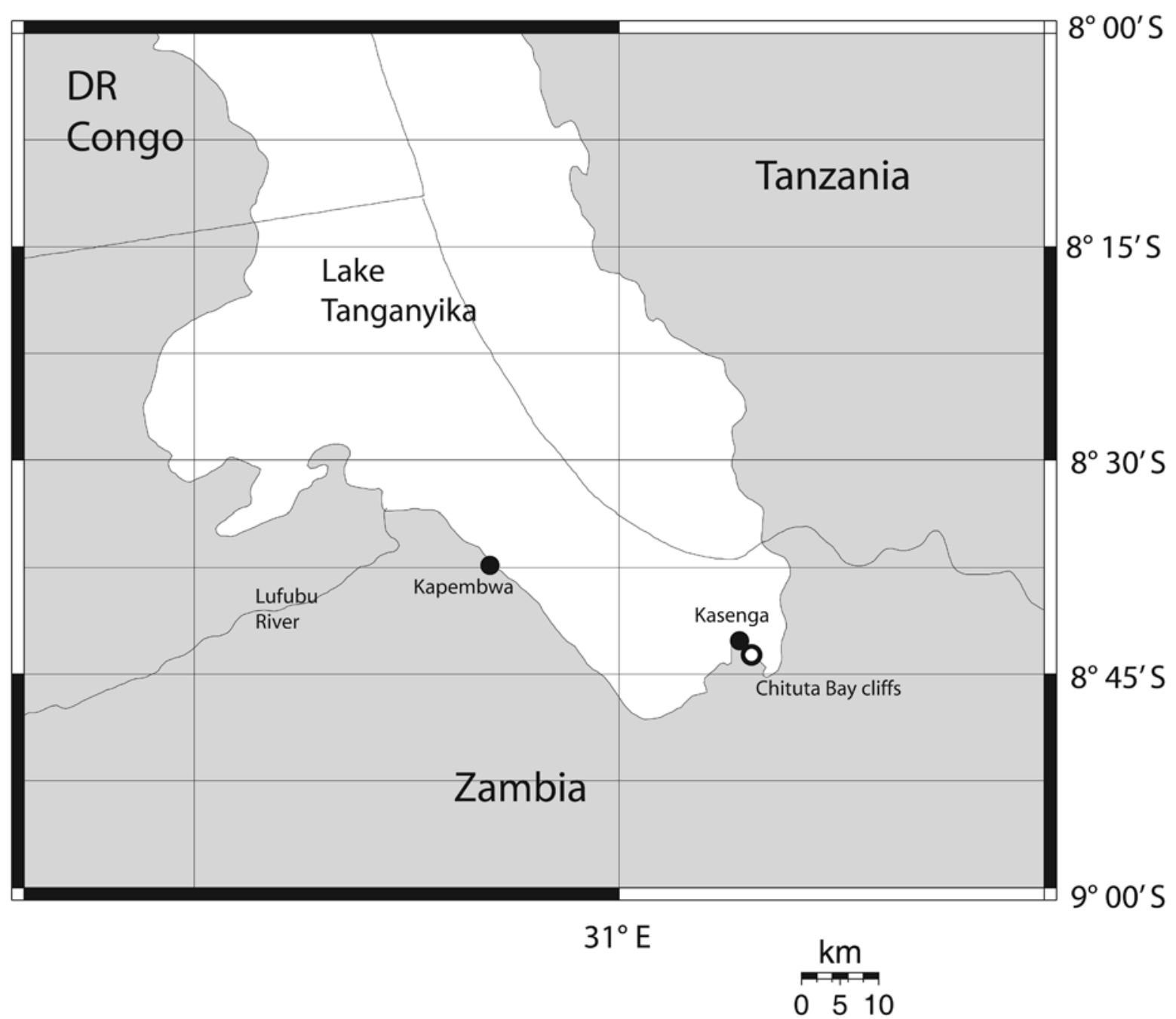

FIGURE 6. Collection localities of Lepidiolamprologus mimicus n. sp. Holotype locality represented by open circle.

Mating and breeding of L. mimicus $\mathbf{n}$. sp. have not been observed despite the long-term underwater survey from 1993 to 2006. However, on two occasions, pairs were observed roaming together for several days around the same area at a depth of 20-25 m. In both cases, the pairs were wandering around a boundary between rocky and sandy substrate, and sometimes inspected holes or crevices among boulders, but did little foraging. 
After the pairs were caught by gill-net underwater, gentle pressure on their abdomens made the males eject semen and females eject mature eggs. These observations suggest that L. mimicus $\mathbf{n}$. sp. is a monogamous species like L. elongatus and L. attenuatus, and not a harem species like L. profundicola (for breeding habit of Lepidiolamprologus, see Kuwamura 1997). It also seems that they breed in rather deep water (more than 30 $\mathrm{m}$ ) beyond the reach of a diving survey. Mature males and females were usually caught with gill-nets in deep water from $20 \mathrm{~m}$ to $50 \mathrm{~m}$ depth.

Distribution. (Fig. 6). Zambian coast of Lake Tanganyika from Kasenga to Kapembwa. The west side of Chituta Bay, the type locality, is characterized by a steep rocky shore starting in the south at the west side of the mouth of the Lunzua River, with usually poor visibility $(<10 \mathrm{~m})$. From the river mouth, where the rocks run to about $5 \mathrm{~m}$ depth, the depth of the rocky slope increases steadily until the point at Kasenga village where it is approximately $50 \mathrm{~m}$ deep. Specimens of Lepidiolamprologus mimicus $\mathbf{n}$. sp. were collected as solitary individuals wandering across the steep sloped rocky habitat, comprised of large rocks and rock slabs (some several cubic meters). Other Lepidiolamprologus occurring sympatrically in Chituta Bay are L. cunningtoni, L. kendalli, L. elongatus, L. attenuatus, and L. profundicola. Only L. nkambae is absent. According to Konings (1988; page 188 and photo on page 121), Lepidiolamprologus mimicus $\mathbf{n}$. sp. also occurs in central Tanzania.

Etymology. The specific name, mimicus, is from the Latin, in reference to the specific feeding ecology involving imitative coloration described herein.

Remarks. Lepidiolamprologus mimicus n. sp. exhibits all of the features that Poll (1986) used to characterize Lepidiolamprologus: a high number of ctenoid scales $(>60)$ in the longitudinal line; more than 20 scales in the lower lateral line; dorsal fin formula XVII-XXI, 10-12; anal fin formula IV-V, 7-9; and large size (140-305 mm TL). In Poll's (1986) classification, Lepidiolamprologus included the following elongate, predatory species: L. elongatus, L. attenuatus, L. profundicola, L. kendalli, L. nkambae, and L. cunningtoni. To the exclusion of L. cunningtoni, L. mimicus $\mathbf{n}$. sp. and the remaining five species of Poll's Lepidiolamprologus all possess an ossification in the labial ligament, two distinct pores at NLF0, forked or stellate gill rakers, scales on the caudal fin to approximately $80 \%$ of caudal length, and three series of spots along the body, situated at the mid-line, upper lateral line, and dorsal fin base.

Mimicry in its various forms is fairly widespread in marine fishes (Randall 2005; Moland et al. 2005). A common form is aggressive mimicry, in which a predatory species resembles a harmless species, allowing it to avoid detection when approaching prey (Wickler 1968). In addition to the numerous marine examples, several tropical freshwater characids, citharinids, and cichlids have been recognized as aggressive mimics (Sazima 2002). Within Lake Tanganyika, aggressive mimicry has been described in scale-eating perissodines (Yanagisawa et al. 1990; Hori \& Watanabe 2000), but this is the first case observed in lamprologines. Interestingly, the abundant schools of brightly-colored Lake Tanganyika cyprichromines are subject to aggressive mimicry from two independent cichlid lineages. Color morphs of Perissodus microlepis with yellow anal fins insinuate themselves into schools of cyprichromines to feed on scales, while yellow-finned Lepidiolamprologus mimicus n. sp. blend into schools to pick off whole fish.

\section{Comparative materials.}

Lepidiolamprologus attenuatus: AMNH 98043 (alcohol and 1 C\&S); MCZ 49254 (alcohol and 1 C\&S); SAIAB 41253; Zm 031-a, 031-b, 05018, 05097-2, 05193, 25041, 840-a.

Lepidiolamprologus cunningtoni: SAIAB 42470 (alcohol and 1 C\&S); MCZ 32596 (1 C\&S); Zm 959$1 \sim 8$.

Lepidiolamprologus elongatus: AMNH 97219; SAIAB 44646 (alcohol and 1 C\&S); Zm 04049-2 3, 04085-1, 04085-3, 04284-1 2, 04284-4 5, 04305.

Lepidiolamprologus kendalli: MRAC 77-36-P-1 (paratype, male, $129.9 \mathrm{~mm} \mathrm{SL}$ ), N. W. of Mutondwe Isl., Zambia, 40 m depth, 16 Nov. 1972; SAIAB 46848 (1 alc); SAIAB 46874 (2 alc); Zm 04088-1 2, 04111-1 2, 04188, 04306, 04621-1 2, 04636. 
Lepidiolamprologus mimicus n. sp.: AMNH 237601 ( $\mathrm{n}=1$; tissue taken), Kapembwa, Zambia, 08³7.37'S, 30 50.87'E, Mar. 10, 2004, R.Bills and R. Schelly.

Lepidiolamprologus nkambae: MRAC 77-49-P-1 (holotype, female, $113.0 \mathrm{~mm} \mathrm{SL}$ ), Nkamba bay, Sumbu National Park, Zambia, Apr. 1975; AMNH 216075 SW (9 C\&S); Zm 04658-1 3, 05696-1 2, 97651-a b, 98138.

Lepidiolamprologus profundicola: MRAC 114.160 (holotype, female, $211.3 \mathrm{~mm} \mathrm{SL),} 114.161$ (paratype, female, 222.2 mm SL), Stat: 68, Baie au Sud immidiat du cap Tembwe, Congo, 15 Jan. 1947; MRAC 114.162 (paratype, male, 246.9 mm SL), Stat: 140, Autour de l'ile de Kabimba, 23 Feb. 1947; MRAC 82.12.P.518-519 (1 C\&S); IRSNB 345 (paratype, male, $167.9 \mathrm{~mm} \mathrm{SL}$ ), collected with holotype; SAIAB 41255; Zm 04004, 04050, 04402, 04463, 04533, 04560-1, 04565, 04570-1, 04597-1 2, 04622-1, 04629-2.

\section{Acknowledgments}

We are very grateful to the Fisheries Department, Agriculture and Natural Resources, Government of Zambia, for their full cooperation and permission to make collections. For assistance in the field, we are also grateful to L. M. Mwape and H. Phiri, and other staff of the Lake Tanganyika Research Unit in Mpulungu, and to Alex Chilala, Lackson Kachali, Ant and Belinda Forster, and John Lundberg. TT and MH express our sincere thanks to H. Kawanabe, and M. Kohda for the opportunity to conduct this study; to J. Snoeks, P. Miguel, G. Lenglet, and P. Campbell for assistance to TT during the examination of type specimens; and to H. Ochi, who provided support and encouragement. RS and RB thank Sally Terry, Barbara Brown, Damaris Rodriguez, Radford Arrindell, and Scott Holtz for assistance with collections. Thanks to Elaine Heemstra for her drawing of the holotype. Funding was provided by a Grant-in-Aid for JSPS Fellows (No. 20188) and Grant-in-Aid for Special Purposes (No. 18779002) for TT, and Grant-in Aid for Scientific Research on Priority Areas (No. 14087203) and Biodiversity Research of the 21st COE (A14) for MH. Additional funding was provided by the Axelrod Ichthyology fund, a Doctoral Dissertation Improvement grant (NSF DEB-0508686), and a Biotic Surveys and Inventories grant (NSF DEB-0542540) for RS and by the All-Catfish Species Inventory (NSF DEB-0315963) for RB.

\section{References}

Aibara, M., Takahashi, T. \& Nakaya, K. (2005) Neolamprologus cancellatus, a new cichlid fish from Lake Tanganyika, Africa. Ichthyological Research, 52, 354-359.

Barel, C.D.N., van Oijen, M.J.P., Witte, F. \& Witte-Maas, E.L.M. (1977) An introduction to the taxonomy and morphology of the haplochromine Cichlidae from Lake Victoria. A manual to Greenwood's revision papers. Netherlands Journal of Zoology, 27, 333-389.

Colombe, J. \& Allgayer, R. (1985) Description de Variabilichromis, Neolamprologus, et Paleolamprologus genres nouveaux du Lac Tanganika, avec redescription des genres Lamprologus Schilthuis, 1891 et Lepidiolamprologus Pellegrin, 1904 (Pisces: Teleostei: Cichlidae). Revue Française des Cichlidophiles, 49, 9-16, 21-28.

Dingerkus, G. \& Uhler, L.D. (1977) Enzyme clearing of alcian blue stained whole small vertebrates for demonstration of cartilage. Stain Technology, 52, 229-232.

Hanssens, M. \& Snoeks, J. (2003) A new species and geographical variation in the Telmatochromis temporalis complex (Teleostei, Cichlidae) from Lake Tanganyika. Journal of Fish Biology, 63, 593-616.

Hori, M. \& Watanabe, K. (2000) Aggressive mimicry in the intra-populational color variation of the Tanganyikan scaleeater Perissodus microlepis (Cichlidae). Environmental Biology of Fishes, 59, 111-115.

Konings, A. (1988) Tanganyika cichlids. Verduijn Cichlids \& Lake Fish Movies, Zevenhuizen, Netherlands, 272 pp.

Kuwamura, T. (1997) Evolution of parental care and mating systems among Tanganyikan cichlids. In: Kawanabe, H., Hori, M. \& Nagoshi, M. (eds.), Fish Communities in Lake Tanganyika, Kyoto University Press, Kyoto, pp. 57-86.

Moland, E., Eagle, J.E. \& Jones, G.P. (2005) Ecology and evolution of mimicry in coral reef fishes. Oceanography and Marine Biology, 43, 455-482. 
Pellegrin, J. "1903" [1904] Contribution a l'étude anatomique, biologique et taxinomique des poissons de la famille des cichlidés. Mémoires de la Société Zoologique de France, 16, 41-400.

Poll, M. (1986) Classification des Cichlidae du lac Tanganika. Tribus, genres et espèces. Académie Royale de Belgique Mémoires de la Classe des Sciences (2 série), 45, 1-163.

Randall, J.E. (2005) A review of mimicry in marine fishes. Zoological Studies, 44(3), 299-328.

Regan, C.T. (1920) The classification of the fishes of the family Cichlidae.--I. The Tanganyika genera. The Annals and Magazine of Natural History (Ser. 9), 5, 33-53.

Sazima, I. (2002) Juvenile snooks (Centropomidae) as mimics of mojarras (Gerreidae), with a review of aggressive mimicry in fishes. Environmental Biology of Fishes, 65, 37-45.

Schelly, R.C. (In press) Lamprologine phylogenetics: Insights from morphology. Journal of Afrotropical Zoology.

Schelly, R., Stiassny, M.L.J. \& Seegers, L. (2003) Neolamprologus devosi sp. n., a new riverine lamprologine cichlid (Teleostei, Cichlidae) from the lower Malagarasi River, Tanzania. Zootaxa, 373, 1-11.

Schelly, R.C., Salzburger, W., Koblmüller, S., Duftner, N. \& Sturmbauer, C. (2006) Phylogenetic relationships of the lamprologine cichlid genus Lepidiolamprologus (Teleostei: Perciformes) based on mtDNA and nuclear sequences, suggesting introgressive hybridization. Molecular Phylogenetics and Evolution, 38(2), 627-646.

Stiassny, M.L.J. (1997) A phylogenetic overview of the lamprologine cichlids of Africa (Teleostei, Cichlidae): a morphological perspective. South African Journal of Science, 93, 513-523.

Sturmbauer, C., Verheyen, E. \& Meyer, A. (1994) Mitochondrial phylogeny of the Lamprologini, the major substrate spawning lineage of cichild [sic] fishes from Lake Tanganyika in Eastern Africa. Molecular Biology and Evolution, $11,691-703$.

Takahashi, T. (2003) Systematics of Tanganyikan cichlid fishes (Teleostei: Perciformes). Ichthyological Research, 50, 367-382.

Takahashi, T., Hori, M. \& Nakaya, K. (2002) New species of Cyprichromis (Perciformes: Cichlidae) from Lake Tanganyika, Africa. Copeia, 2002(4), 1029-1036.

Takahashi, T. \& Hori, M. (2006) Description of a new Lake Tanganyikan cichlid fish of the genus Cyprichromis (Perciformes: Cichlidae) with note on sexual dimorphism. Journal of Fish Biology, 68 (Supplement B), 174-192.

Wickler, W. (1968) Mimicry in plants and animals. McGraw-Hill, New York, 255 pp.

Yanagisawa, Y., Nshombo, M., Nishida, M. \& Niimura, Y. (1990) Sexual dichromatism and feeding habits of the scaleeater Plecodus straeleni (Cichlidae, Teleostei) in Lake Tanganyika. Journal of Ethology, 25-28. 
